\title{
O'manam
}

$\triangle \nabla \Delta \nabla \Delta \nabla \Delta \nabla \Delta \nabla \Delta \nabla \Delta \nabla \nabla \nabla \nabla \Delta \nabla \Delta \nabla \Delta \nabla \Delta \nabla \Delta \nabla \Delta \nabla \nabla \nabla \nabla \Delta \nabla \Delta \nabla \Delta \nabla$

DOI 10.31418/2177-2770.2021.v13.n.38.p22-45 | ISSN 2177-2770 Licenciado sob uma Licença Creative Commons

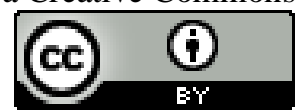

\section{COMPREENSÕES SOBRE A CONSTRUÇÃO SUBJETIVA DE MULHERES NEGRAS}

\author{
Thainá da Silva Costa \\ Universidade Estadual Paulista, Programa de Pós-graduação, Departamento de \\ Psicologia e Sociedade, Assis, SP, Brasil. \\ Leandro Amorim Rosa \\ Universidade Federal do Acre, Centro de Filosofia e Ciências Humanas, Curso de \\ Psicologia, Rio Branco, Acre.
}

Resumo: A discussão da temática étnico-racial nas ciências humanas se faz necessária para pensar uma prática equiparável da atuação em Psicologia, diante a violência racial sofrida pela população negra brasileira. $\mathrm{O}$ artigo objetiva fomentar, através das produções do Conselho Federal de Psicologia, das psicólogas e pesquisadoras Clélia Prestes e Sueli Rolnik, também das intelectuais Helena Theodoro, Lélia Gonzalez e Sueli Carneiro, a discussão de tal temática através de entendimentos sobre a construção subjetiva de mulheres negras brasileiras. Deste modo, aludimos, neste texto, as principais consequências da violência racial, de gênero e de classes que atingem estas mulheres, de modo a compor suas subjetividades. Por resultado, obtivemos contato com histórias de sofrimento e adoecimento físico, moral e psíquico fundados nas violências de classe, gênero e étnico-raciais. Porém, pelas contribuições de Terezinha Bernardo, Beatriz Nascimento e Márcia Figueiredo Tokita foi possível também identificar uma história de resistência por meio de diversos processos de enfrentamento, como a resiliência, ofertando um posicionamento na luta social e política e identificação étnico-racial de mulheres negras brasileiras.

Palavras-Chave: Mulher negra; Subjetividade; Sofrimento; Resiliência

\section{UNDERSTANDINGS ABOUT THE SUBJECTIVE CONSTRUCTION OF BRAZILIAN BLACK WOMEN}

\begin{abstract}
The discussion of the ethnic-racial issue in Psychology has been necessary to think about the racial violence suffered by the Brazilian black population. The article proposes to foster the discussion of the subject in Psychology throuthg the possible understanding the subjective construction of Brazilian black women. Thus, we will allude in this text to racial violence, as well as gender and class violence, which affect these women and construct their subjectivity. As a result, we managed to discuss a history of suffering and physical, moral and mental illness, based on class, gender ethnic-racial violences. However, it was also possible to identified a story of resistance through various
\end{abstract}


coping processes, such as resilience and nomadic subjectivity, offering a place in the fight against discrimination and ethnic-racial identification the Brazilian black women.

Keywords: Black woman; Subjectivity; Suffering; Resilience

\section{COMPRENSIONES SOBRE LA CONSTRUCCIÓN SUBJETIVA DE LAS MUJERES NEGRAS BRASILEÑNAS}

Resumen: La discusión de las etnias-raciales en psicología ha sido necesaria para pensar en la violencia racial que sufre la población negra brasileña. El artículo propone fomentar la discusión del tema en Psicología, mediante la comprensión de la posible construcción subjetiva de las mujeres negras brasileñas. Por lo tanto, aludiremos en este texto a la violencia racial, así como a la violencia de género y de clase, que afecta a estas mujeres y construye esta subjetividad. Como resultado, nos pusimos en contacto con una historia de sufrimiento y enfermedades físicas, morales y mentales, donde a través de la triple violencia pueden construir sus subjetividades a través de estos efectos negativos. Y también identificamos una historia de resistencia a través de varios procesos de afrontamiento, como la resiliencia y la subjetividad nómada, que ofrecen la posición en la lucha y la identificación étnico-racial de las mujeres negras brasileña.

Palabras-clave: Mujer negra; Subjetividad; Sufrimiento; Resiliencia

\section{COMPRÉHNSION DE LA CONSTRUCTION SUBJECTIVE DES FEMMES NOIRES BRÉSILIENNES}

Résumé: La discussion sur le thème ethno-racial en psychologie a été nécessaire pour réfléchir à la violence raciale subie par la population noire brésilienne. L'article propose de favoriser la discussion sur le sujet en psychologie, en comprenant possible de la construction subjective des femmes noires brésiliennes. Ainsi, nous ferons allusion dans ce texte à la violence raciale, ainsi qu'à la violence sexiste et de classe, qui affectent ces femmes et construisent cette subjectivité. En conséquence, nous avons pris contact avec unhistoire de souffrance et de maladies physiques, morales et mentales, où la triple violence peut renforcer leurs subjectivités grâce à ces effets négatifs. Et nous avons également identifié une histoire de résistance à travers divers processus d'adaptation, tels que la résilience et la subjectivité nomade, offrant le posiocionamneto dans la lutte et l'identification ethno-raciale des femmes noires brésiliennes.

Mots-clés: Femme noire; La subjectivité; La souffrance; La résilience.

\section{INTRODUÇÃO}

Por muito tempo, as diversas violências cometidas contra as mulheres negras davam-se por invisíveis e inexistentes. A violência de gênero passou a ser entendida como atravessamento concomitante e paralelo à violência de raça na vida de mulheres negras apenas no século XX, tornando-se evidente a partir desse período. Após a década de 1970, 
com o surgimento da terceira onda do feminismo, o recorte de raça é levado para dentro do debate de gênero nos movimentos feministas havendo um aumento na visibilidade e no reconhecimento das segregações vivenciadas entre tais mulheres. Segregações essas como as violências direcionadas à sua orientação afetiva, classe social e etnia, que até então eram vivenciadas diariamente, mas não consideradas nas pautas e lutas dos movimentos sociais (LIMA, 2013).

Por meio do fomento das discussões destas pautas por ativistas negras, pela produção de vários conceitos - como o de intersecção (CRENSHAW, 2004) - e da compreensão de que estas violências juntas formam um nó (SAFFIOTI, 2004), atingindo a vida dessas mulheres, há o aumento da visibilidade para as violências até então invisíveis. As questões raciais têm sido incluídas nas discussões de gênero e direitos humanos, assim como as questões de gênero incluídas nas discussões de raça e direitos humanos, gerando uma compreensão sobre a discriminação interseccional. No entanto, ainda há certa dificuldade em "incorporar a questão de gênero à prática dos direitos humanos e a questão racial ao gênero" na efetivação de políticas públicas (CRENSHAW, 2004, p. 9).

Segundo a autora norte-americana Kimberle Crenshaw (2004), a interseccionalidade é o entendimento que sugere que as situações vivenciadas de gênero não dizem respeito somente ao grupo de mulheres, ou que as questões de raça não dizem respeito apenas à etnia e as questões de classe apenas aos pobres, ou seja, que, podendo duas ou mais violências atravessarem o mesmo grupo. O gênero, a etnia e a classe social fazem parte da construção do sujeito. A partir dos atravessamentos destas forças e fluxos, ocorre a formação das mulheres negras ao longo de suas vidas (SAFFIOTI, 2004). A consideração e interpretação das diferenças vinculadas às diversas possíveis intersecções são necessárias, já que tantas forças e atravessamentos constituem essas mulheres (RIBEIRO, 2017).

Podemos compreender que há uma imbricação entre as determinações de classe, de sexo e de raça. Segundo a autora Heleith Saffioti (2004), as violências vinculadas a esses três lugares sociais entrelaçadas em um nó mantém o sistema capitalista. Sendo assim, os marcadores, ou caracteres de sexo e raça, operam como marcadores sociais que hierarquizam por meio de padrões e valores estabelecidos de um processo historicamente construído. O sexo torna-se um fator de inferiorização social da mulher e interfere para a 
competitividade na contribuição de classes sociais; e, quando falamos em mulheres negras, esse fator é agravado pelo marcador de raça que potencializará a imposição de obstáculos à realização plena da mulher negra na sociedade (SAFFIOTI, 1978).

Tratar das discriminações raciais e de gênero é entender a discriminação denominada por mista ou composta, ou seja, é compreender os efeitos da combinação da violência racial e violência de gênero, que são duas formas diferentes de discriminação. Tal visão rompe com a tradicionalidade das discriminações que não consideram essas sobreposições. A intenção de trazer esta discussão é considerar que há combinações de segregações que afetam a vida de determinados grupos de pessoas. Quando é trazida a reflexão sobre mulheres negras, estamos na tentativa de elucidar as segregações específicas vivenciadas por este grupo de pessoas (CRENSHAW, 2004).

A filósofa política Djamila Ribeiro (2017) contribui para as reflexões de raça e gênero. Em seu livro "O que é lugar de fala", deixa claro que o lugar da mulher negra é um lugar de invisibilidade social de sua fala e desigualdades, que sempre vivenciou. Fica evidente tal silenciamento nas primeiras lutas feministas vividas por mulheres brancas que universalizavam suas pautas, como se suas realidades, enquanto mulheres brancas, fossem iguais às realidades vividas por mulheres negras, gerando assim um olhar excludente das diferentes violências sofridas por mulheres negras. Nas primeiras reivindicações feministas, lutava-se por igualdade, porém tal igualdade era neutralizada e invisibilizava as desigualdades vividas pelas mulheres negras (SAFFIOTI, 2004). Raça e gênero configuram a construção da mulher negra brasileira. A raça classifica e atravessa o gênero, ambos são marcações, combinações de segregações que delimitam espaços para essas mulheres ocuparem socialmente (LIMA, 2013).

Segundo a psicóloga Lia Vanier Schucman (2014), o racismo consiste na inferiorização de algumas raças sobre outras, ele é considerado como um meio de justificar as "diferenças, preferências, privilégios, dominação, hierarquias, e desigualdades materiais e simbólicas entre os seres humanos" (SCHUCMAN, 2014, p. 85). As práticas do racismo foram embasadas no conceito de raça, o qual se estruturou e tomou força ao longo dos tempos na sociedade. Esse conceito de raça, que dá suporte e base para o racismo surgir e justificar suas violências, nasce na biologia e na antropologia física para dividir, assim como no mundo animal, os seres humanos em subespécies (WEDDERBURN, 2007). Essa separação estaria associada ao "desenvolvimento 
diferencial e de valores morais, de dotes psíquicos e intelectuais entre os seres humanos" (GUIMARÃES, 2003, p. 95). Historicamente o conceito de raça repercutiu no mundo de modo danoso, como a hierarquização - modo de subjugar as raças que eram diferentes de outras.

As violências de gênero e raça geram uma realidade social que podemos mensurar através de cálculos estatísticos. Tais estatísticas, as quais enquadram mulheres negras em determinada classe social pela sua etnia e gênero, são alarmantes no Brasil. Conforme dados do Instituto de Pesquisa Aplicada (IPEA) em 2013, 5,5\% delas encontravam-se em extrema pobreza (IPEA, 2016) e 15\% destas em 2015 chegaram ao Ensino Superior (IPEA, 2015). Colocam-nas também em uma posição de violação do seu corpo e fim da sua vida, pois, nos últimos 10 anos, os homicídios contra mulheres negras tiveram um aumento de 54,2\% (IPEA, 2016) e 88,5\% dos casos de estupros foram contra pessoas pretas e pardas (SINAN; DATASUS, 2011, citado em IPEA, 2016). Em relação ao encarceramento de mulheres, no Brasil, cresceu cerca de $567 \%$ o número de mulheres encarceradas e, quando vemos o perfil destas mulheres, identificamos que são mulheres de baixa renda, em serviços terceirizados e com baixa escolaridade, ou seja, enquadradas no perfil das mulheres negras do país (INFOPEN, 2014 citado em IPEA, 2016).

Tais violências deixam vulneráveis as mulheres negras, sendo essas mais suscetíveis a homicídios, encarceramento e ocupação em serviços terceirizados de baixa remuneração. O racismo e o sexismo atravessam-nas ao ponto de impor papéis para ocuparem, por exemplo, a forma como aparecem nas Telenovelas interpretando domésticas e, na vida real, são, supostamente, também domésticas e aquelas cheias de fogosidade, as que não sofrem, pois são fortes. Segundo o Conselho Federal de Psicologia - CFP (2017) estes papéis ofertam à mulher negra a experiência de sofrer seu próprio corpo - formado socialmente sob tantas influências. A etnia negra e o gênero mulher são carregados de estereótipos e papéis na sociedade, o que influencia no sofrimento dessas mulheres. O ser-negra e o ser-mulher são carregados de conceitos estabelecidos daquilo que se espera de uma mulher negra, por exemplo "toda mulher negra deve saber sambar", “toda mulher negra é forte e aguenta alta intensidade de dores". Para Frantz Fanon (2008, p. 104) o preto carrega uma maldição corporal, ou seja, carrega lendas, histórias e estereótipos, "no mundo branco, o homem de cor encontra dificuldades na elaboração do 
seu esquema corporal". Para a sociedade, "o preto é um animal, o preto é ruim, o preto é malvado, o preto é feio; olhe, um preto!" (FANON, 2008, p. 106).

Sueli Carneiro (2003), Thainá Costa e Lilian Cantelle (2018) afirmam que os papéis sociais dados a essas mulheres permanecem desde a escravidão até a contemporaneidade intactos, pois, de maneira atroz, as relações de gênero são racializadas. Destarte estão presentes na imagem que atrelamos a estas mulheres negras. "Ao imediatamente ver uma mulher negra, atrelamos a sua imagem à de uma cozinheira ou doméstica, ou de uma mulher que serve apenas para o sexo, mas não para casar e formar uma família" (COSTA; CANTELLE 2018, p. 50). Carneiro (2003) também traz ao debate a questão do mito da fragilidade ligado ao gênero feminino, indagando em qual momento histórico as mulheres negras foram tratadas como frágeis. Esta reflexão elucida a diferença da violência de gênero entre mulheres brancas e negras, pois as últimas nunca foram tratadas como frágeis. Ressalta também que essas mulheres sempre trabalharam na lavoura, nas ruas, como vendedoras, prostitutas e tantas outras mais ocupações e não entendiam quando as feministas lutavam pelo direito ao trabalho e pelo direito de ir às ruas, pois já trabalhavam e ocupavam as ruas há muito tempo. A reflexão de Carneiro demonstra a agressividade que a estrutura da sociedade tem para com as mulheres negras. A ativista Sojourner Truth (GELEDÉS, 2009, citado por RIBEIRO, 2017) foi uma das pioneiras no ativismo da luta feminista negra. Em um discurso improvisado denominado “Não sou uma mulher?” - pronunciado em 1851, na Convenção dos Direitos da Mulher em Akron, Ohio -, a ativista afirmou que as mulheres negras não eram consideradas sequer como mulheres. Quando um cavaleiro via uma mulher branca passar na rua e essa estava prestes a pisar em um lamaçal ou a subir em uma carruagem, recebia logo o auxílio de um homem. Já para com as mulheres negras, o mesmo não acontecia, visto que eram insignificantes para os homens.

No poema de Ryane Leão - poeta negra brasileira - encontrado no seu livro "Tudo nela brilha e queima", vemos a exemplificação desta construção social de coisificação, objeto sem valor que as mulheres negras brasileiras enfrentam. A autora diz: "Parece que sou uma planta e me arrancaram da terra com força violenta e me apalparam e tatearam sem consentimento esqueceram que tenho raízes" (LEÃO, 2017, p. 50). No trecho, vemos a violência de raça que afasta do resgate cultural e identitário e a violência de gênero que vê este corpo como objeto, coisificação e não como sujeito. Pensar sobre 
mulheres negras é vislumbrar as combinações de discriminações de raça e discriminações de gênero, ou seja, sua interseccionalidade, e imbricações que resultam no nó. Esta situação as coloca como alvo de violências, as quais as atravessam de tal modo a propiciar uma construção de objeto, coisa, e não de sujeito (SOUZA, 1983). Tais aspectos contribuem na formação da mulher negra, enquanto subjetividade e identidade, gerando consequências como o adoecimento psíquico.

Sendo assim, o objetivo deste artigo é elucidar as vivências vinculadas à produção de subjetividade de mulheres negras através do diálogo com produções de Clélia Prestes, Frantz Fanon, Lucas Veiga, CFP, dentre outras. Dando continuidade ao artigo, o próximo tópico contará com as reflexões da construção subjetiva de mulheres negras, por meio das produções teóricas de Sueli Rolnik. Também contará com as contribuições de Lucas Veiga no intuito de oferecer a compreensão de como se constitui a subjetividade de uma mulher negra, diante de uma sociedade racista, sexista e classista. Neste tópico, serão esboçadas as possíveis consequências desta construção subjetiva, sendo o sofrimento dessas mulheres elucidado por Clélia Prestes, Frantz Fanon e os Cadernos temáticos do CFP.

Em seguida, traremos a compreensão de que essas mulheres carregam consigo o símbolo da resistência e resiliência diante destas vivências, ou seja, mulheres que se emancipam frente às feridas do racismo, através de uma subjetividade nômade, conceito ilustrado por Rosi Braidotti. Compreenderemos também o conceito de resistência refletido por Terezinha Bernando e Márcia Figueiredo Tokita, e o conceito de resiliência esboçado pela psicóloga Clélia Prestes. Esperamos contribuir para os estudos de Psicologia sobre a temática, para fomentar a descolonização da Psicologia e proporcionar atuações e práticas que rompam com a práxis da Psicologia higienista e branca, que adoece a população negra, cumprindo deste modo com o código de ética da profissão que diz que toda (o) psicóloga (o): "Trabalhará visando promover a saúde e a qualidade de vida das pessoas e das coletividades e contribuirá para a eliminação de quaisquer formas de negligência, discriminação, exploração, violência, crueldade e opressão" (CFP, 2017, p. 10)

\section{SUBJETIVIDADE, RAÇA GÊNERO}


Como vimos anteriormente, as mulheres negras sobrevivem em uma sociedade constituída e constitutiva da violência. Segundo as construções sociais a partir da época colonial, a população negra e essas mulheres experenciam um processo de desintegração de si, são expostas a um grande sofrimento oriundo da violência do racismo e sexismo desde a escravidão. A colonização afastou o sentido de ser humano, de ser livre, do sentido africano de viver, vivendo e pensando assim o povo africano como povo colonizado (VEIGA, 2018).

Desde então, vivemos em uma sociedade que estabelece padrões de normalidade, onde temos o padrão e o ideal como: homem, branco e hétero. Esses padrões baseiam-se nas estruturas de violência e estabelecem um determinado modo de ser no mundo. $\mathrm{O}$ padrão gera e perpetua a violência, quanto mais fora desse padrão, mais suscetível a sofrer violência. Pensar as subjetividades de mulheres negras é entender que "vivemos em um país antinegro e isso tem nocivos efeitos sobre as subjetividades negras" (VEIGA, 2018, p. 79).

Segundo o intelectual francês Fanon (2008), o racismo e colonialismo foram modos socialmente geradores de visões de mundo, uma maneira de estruturar e estabelecer a sociedade pela desigualdade e exploração. A partir do colonialismo, as pessoas constituíram uma linguagem, uma ciência, uma expressão e também uma forma de entendimento. Tais aspectos geraram impactos que permeiam a sociedade e a construção subjetiva das mulheres negras na contemporaneidade, os descendentes africanos mesmo não tendo vivido na época colonial carregam em seus corpos e memórias marcas deste período (VEIGA, 2018). Entendemos que todo povo colonizado foi um povo que nasceu no seio de um complexo de inferioridade, oriundo da morte de sua cultura originária pelo processo colonizador. Há um sentimento de inferioridade entre os negros, e parte de tal população tenta eliminar esse sentimento rejeitando a "negridão" e aproximando-se da brancura (FANON, 2008).

Diferentemente da mulher branca, as mulheres negras vivem uma condição existencial específica pela cor da sua pele e pelo seu gênero: a de conviver diariamente com uma construção subjetiva que inibe a sua autenticidade em ser mulher negra. $\mathrm{O}$ racismo exerce esta violência na sociedade brasileira a partir das suas várias manifestações. A formação subjetiva e o sofrimento psíquico vão se configurando na população negra feminina desde a sua infância, desde os primórdios de sua existência no 
mundo. Persuadida pelo racismo, ela é impelida a buscar aquilo que é aceitável socialmente: o ideal branco, como vimos anteriormente. Ela se anula, absorve e inala os ares estruturais do racismo. De forma alienada, busca por essa subjetividade branca, engessada, que não é sua subjetividade, e que a faz se distanciar do seu corpo, da sua história étnica, pessoal e da sua resistência. Por mais que a própria mulher afro-brasileira reproduza e viva tal condição, - condição, esta, de aniquilamento étnico e busca pelo branqueamento - o sofrimento está presente, pois seu corpo é de uma mulher negra, e não de uma mulher branca, e aderir às características brancas lhe fará repudiar sua pele negra e desejar ser outra pessoa, um alguém branco (SOUZA, 1983).

Segundo Rolnik (1997), a construção subjetiva de todo ser humano se dá em um contexto social, cultural, ideológico e institucional. Rolnik (1997, p. 1) traz a concepção de subjetividade como um "tecido vivo e móvel, feito das forças/fluxos que compõem os meios variáveis que habitam a subjetividade: meio profissional, familiar, sexual, econômico, político, cultural, informático, turístico, etc.” Maria Helena Rodrigues Navas Zamora (2012, p. 564) também afirma que "a subjetividade é algo modelado, produzido por processos coletivos, institucionais, sociais, que atravessam os indivíduos”. Ela não se estagna, mas está em constante movimento. A partir das forças e fluxos exteriores, modifica-se e forma combinações com novas forças e fluxos, que ali adentram o mundo subjetivo. As forças e fluxos que surgem da sociedade racista atravessam a construção das subjetividades, o que pode não impedir, mas dificultar o tornar-se negro (SOUZA, 1988).

Nesta construção subjetiva, o racismo apresenta-se como um modo que interfere no existir da população negra e, consequentemente, na mulher integrante desta população, ou seja, interfere no processo de socialização e subjetivação (CFP, 2017). A população afrodescendente que vivência a violência racial, poderá passar por transtornos de pensamento e comportamentos, além de sentimentos de inferioridade e comportamentos de caráter isolado, que serão compreendidos por agressividade ou timidez (SANTOS, 2017).

Como vimos acima, a subjetividade é construída a partir dos afetos sociais, institucionais, dentre outras relações humanas possíveis. Portanto, na construção subjetiva dessas mulheres brasileiras está presente a violência racial e também de gênero. Neste sentido, o CFP (2017) colabora para nossa compreensão de que as mulheres negras 
são submetidas a uma produção subjetiva afetada pelo racismo. Afirmando que o racismo, violência racial real, se expressa de três formas: institucional, intersubjetivo e internalizado. Mais uma vez, podemos pensar e entender que, desta maneira, a base da construção subjetiva de tais mulheres brasileiras seja a da violência advinda do racismo. O racismo institucional, surge com esta denominação em 1967, com os ativistas Stokely Carmichael e Charles Hamilton, integrantes do movimento dos Panteras Negras nos Estados Unidos da América, e é uma prática que possibilita a não percepção real do racismo (CFP, 2017). Entende-se, como racismo institucional, privilégios ou negligências que as instituições utilizam em suas gestões, o que produz condições desfavoráveis de vida à população negra e também indígena, sendo tal prática mola propulsora para a população branca.

Tal definição representa os dados expressos no tópico inicial deste texto, que trata das desigualdades nas quais a mulher negra enquadra-se no grupo que mais sofre violência e que mais está em estado de vulnerabilidades. Tais mulheres também são afetadas pelas não oportunidades de outros empregos que ofereçam ascensão social, assim como pela falta de acesso à saúde e à educação. O racismo institucional dificulta a essas, e à população negra em geral, ascender socialmente. Esta prática exerce ações que perpetuam o lugar da negra e do negro à margem social (PRESTES, 2013). Além disso, exerce uma desqualificação de tal população, não reconhecendo a contribuição dos negros para as áreas das ciências e do progresso do país, ou seja, exerce uma negação da contribuição da população negra na formação da identidade brasileira (CFP, 2017).

Diferentemente, no racismo intersubjetivo, a violência racial apresenta-se no meio relacional em que a pessoa negra está inserida, ou seja, nas relações familiares, pessoais e profissionais. O racismo intersubjetivo se expressa em uma condição de desigualdade, totalmente embasada na cor/etnia, em que pessoas não negras se favorecem em detrimento de pessoas negras. A partir da cor/etnia a violência racial é exercida por meio de preconceitos e discriminações postas. Nestas situações, os relacionamentos geralmente produzem humilhações e desqualificações contra pessoas negras, como por exemplo:

Usuárias (os) negras (os) de serviços públicos e privados de saúde recebem tratamento de menor qualidade do que usuárias (os) brancas (os), incluindo o tempo de consultas (...) Quando profissionais em cargos de chefia exigem que profissionais negros devam prender o cabelo mas a função realizada não exige 
cabelo preso e outros profissionais não negros não recebem a mesma orientação. Amigos ou conhecidos com piedade de pessoas negras pelo fato de serem negras. Não apresentação pública por parte da pessoa branca de relacionamentos amorosos/sexuais que envolvam negros (as). Não reconhecimento formal ou afetivo ou menosprezo do (a) filho (a) negro (a) por parte do (a) progenitor (a) não negro (a) (CFP, 2017, p. 55).

O racismo intersubjetivo ocorre nas relações de maneira vertical e horizontal. Mas, quando falamos da mulher negra e da população LGBT+, trata-se de uma discriminação entrecruzada, uma discriminação, humilhação, desqualificação que é realizada com base na cor/etnia, no gênero e na orientação sexual, uma discriminação reforçada pela violência de gênero (CFP, 2017). O racismo intersubjetivo contribui significativamente para o processo de afastamento da carga étnica/histórica da mulher negra e para o vício subjetivo no modelo branco, pois, para evitar os conflitos que o racismo intersubjetivo proporciona, pode afastar-se de si mesma. As tensões geradoras do racismo intersubjetivo interferem na construção subjetiva desta mulher. A partir desta construção subjetiva, ela não se vê, não se encontra na mídia, nos livros, na história do Brasil. O racismo intersubjetivo faz com que a mesma não se reconheça na afrobrasilidade.

No racismo internalizado, as mulheres negras - por coerção - e as mulheres brancas -por adquirirem benefícios - interiorizam o racismo e agem de modo que suas atitudes alimentam o imaginário social e a hierarquização entre as raças. Esse conceito é semelhante ao conceito de sujeito-suposto-saber de Lacan interpretado por Lélia Gonzalez (2011), no qual o indivíduo negro internaliza em si o ser inferior, e o ser superior é atribuído ao branco, o que justifica a esquiva aos enfrentamentos com o branco em situações racistas. Fanon (2008) também aborda o racismo internalizado ao expressar que o negro nasce com o sentimento de inferioridade, e o branco desde a infância atribui ao negro estereótipos. O autor exemplifica o racismo internalizado ao trazer um caso do livro do escritor Aime Césaire, no qual o personagem negro dúvida veementemente de receber uma resposta positiva amorosa de uma mulher branca, esquivando de the fazer o pedido matrimonial por ser negro, sentindo-se inferior a ela e duvidando do amor que a mesma diz ter por ele. Fanon (2008) também continua exemplificando tal violência ao trazer um relato de temor de um menino branco por um homem negro.

Faz frio, o preto treme, o preto treme porque sente frio, o menino treme porque tem medo do preto, o preto treme de frio, um frio que morde os ossos, o menino 
bonito treme porque pensa que o preto treme de raiva, o menino branco se joga nos braços da mãe: mamãe, o preto vai me comer! (FANON, 2008, p. 107).

O branco, no racismo internalizado, exerce uma energia significativa em perpetuar o racismo, no sentido de demandar muita energia para as ações racistas ao invés de demandar energia para gerar mudanças e ações contra esta violência. Desse modo, o racismo internalizado pode ser consciente da parte daquele que exerce a violência e daquele que sofre o golpe, ou inconsciente em ambos. A dificuldade da superação da violência racial está presente não somente nos privilégios e benefícios adquiridos com a prática discriminatória, mais também pelo simples fato de sempre evidenciar o ato presente no outro e não em seus agentes, o que torna a violência perceptível mais não assumida por aquele que prática (SANTOS, 2017). Entretanto, mesmo quando aquele que lança o golpe o faz inconscientemente, ele adquire invariavelmente benefícios. Enquanto aquele que recebeu o golpe, mesmo que seja inconsciente, carrega marcas simbólicas, mesmo que não entenda a razão da violência sofrida (CFP, 2017).

Vale destacar, que o adoecimento psíquico oriundo das práticas da violência racial, presente nessas três formas de expressão discriminatórias, adoece a população afrodescendente, porém tal sofrimento não é valorado, haja visto o argumento que somente a população da classe dominante estar suscetível ao processo de adoecimento pela depressão. Compreende-se que os mais de 500 anos de sofrimento ou "Banzo" da população negra são desqualificados pela população branca, trivializado e estereotipado, afetando potencialmente o agravo da doença, tornando-a ilegítima (SANTOS, 2017).

A compreensão do racismo institucional, intersubjetivo e internalizado leva-nos a perceber como o racismo - violência racial real - interfere de forma relevante na produção subjetiva de mulheres negras e como produz um sofrimento significativo. Isto explica o motivo de muitos casos de paralização e vícios de subjetividade, nos quais esta não se movimenta, mas é subjugada pelas violências e sofrimentos.

Os efeitos psicossociais na mulher negra que sofre o racismo podem ser entendidos através de mecanismos psíquicos de defesa, como o da negação e a identificação com o agressor. Tais mecanismos ocorrem para manter a integridade psíquica e intersubjetiva. Um segundo efeito pode ser o de dilaceramento psíquico, no qual tais mulheres vivenciam a violência de modo catastrófico, necessitando de ajuda para se refazer do trauma experienciado a partir de terapia individual, familiar e uso das 
políticas públicas (CFP, 2017). Prestes (2013) também contribui para o entendimento do sofrimento psíquico dos afetos pelo racismo e sexismo. O racismo interfere na dinâmica intra e interpsíquica do indivíduo em suas relações individuais, institucionais, familiares, afetivas e sociais. A autora defende que, do ponto de vista emocional, econômico, cultural, sanitário, programático, educacional, profissional e cidadania a população negra terá diversos prejuízos.

Identificamos que as consequências de uma produção subjetiva, oriundas do racismo, exercem contra a mulher negra um sofrimento psíquico significativo. A violência do racismo não se limita apenas à construção subjetiva viciada no modelo social, mas também a afeta negativa e violentamente. Por isso, em função do racismo, ela tenta e afasta-se das circunstâncias que a aproxima da sua negritude, do seu grupo, do contato com outros negros e de características fenotípicas (cabelo crespo, pele negra, cultura afro-brasileira). Podemos entender que está construção subjetiva, afastada de si mesma, é um processo de defesa contra a humilhação e a angústia, ou seja, defesa de um sofrimento psíquico vivido não só por esta mulher hoje, mas por um longo tempo político e histórico, com seus antecessores e antepassados (CFP, 2017).

Agregada à violência de raça, a violência de gênero pode moldar as subjetividades das mulheres negras e os papéis sociais destas no país, como, por exemplo, a imagem de fogosidade na cama, de ausência de sentimento de dor e de ser aquela que tem o samba no pé. Há um impacto sobre estas subjetividades e a geração de sofrimento. O racismo, as discriminações, os estereótipos e o sexismo, ao interferirem na formação de suas subjetividades, colocam-nas em posição de vulnerabilidade e, como consequência, há um impacto negativo sobre elas, sendo recorrente o comprometimento de sua saúde orgânica/psíquica (PRESTES, 2013). Em decorrência desta realidade, vivem constantemente em estado de defesa, e experimentam a desqualificação, desvalorização e invisibilidade de suas necessidades, sendo colocadas, neste sentido, em constante vulnerabilidade (THEODORO, 2008). A rejeição a qual tais mulheres estão expostas diariamente, como a rejeição da sua cor, da sua ancestralidade, do seu cabelo crespo, da sua intelectualidade provocam feridas que vão até o coração, como afirma Prestes (2013), e, quando internalizadas, levam estas mulheres a rejeitar a si mesmas.

Ressaltamos que, apesar de todo este sofrimento psíquico e violência subjetiva, a Psicologia, como ciência, historicamente se omitiu perante as humilhações e todas as 
consequências desse processo. Ignorava as demandas que surgiam em sua atuação, sejam no âmbito clínico, escolar, organizacional, na saúde ou em outras áreas. Com essa atitude, pactuava e colaborava com as práticas que, em tantos momentos, foram causadores de mortes e adoecimentos contra a população negra (PRESTES, 2013). Neste sentido a perpetuação da população negra no sofrimento, consiste numa vivência constante de sentimento de perseguição, angustia e ansiedade. Tais sentimentos podem desencadear distúrbios de pensamentos, como o sentimento de culpa, causando diversas disfunções psíquicas e físicas, incluindo, ataques de pânico, alcoolismo, hipertensão entre outras causas. Estes sentimentos desencadeados por pensamentos de culpa que ocasionam disfunções, geralmente são consequências da ausência de ações em políticas públicas, socioeconômicas, e atuações efetivas na Psicologia (SANTOS, 2017). É recente a inserção da Psicologia na interação do assunto e as produções sobre o tema ainda são escassas. Tal postura tem causado significativo atraso no combate ao racismo e fortalecimento psíquico da população afrodescendente.

Apesar de toda a violência, a mulher negra tem seus modos de enfrentamento, ou seja, sua resistência. Podemos pensar que, ao mesmo tempo em que há mulheres negras que se paralisam no sofrimento psíquico e na construção subjetiva engessada, há mulheres negras que, por meio de suas próprias estratégias e/ou auxílio e suporte profissional, utilizam do sofrimento como uma maneira de movimentar-se e resistir politicamente, afirmando e resgatando a cultura e sua história no nosso país. Assim, a mulher negra foge da visão controlada sobre si e transforma-se, encontra-se e aproxima-se de si mesma ao tornar-se negra (SOUZA, 1983).

\section{MULHERES QUE SE EMANCIPAM FRENTE ÀS FERIDAS}

Diante do que tem sido apresentado no artigo, identificamos que as mulheres negras no país experienciam um sofrimento ético-político, ou seja, caracterizado pela sua situação social. Situação essa de uma sociedade conflituosa, que abarca as violências que as ferem, especificamente na vivência dos sujeitos em posição subalterna no processo de luta de classes. Em decorrência desse sofrimento ético-político, surge o sentimento dessas mulheres serem consideradas e determinadas como pessoas inúteis à sociedade, subalternas, sem valor e inferiores (SAWAIA, 1999). Entretanto, essas subjetividades, 
permeadas pelos sofrimentos, suas manifestações e também pelos processos de construção subjetiva, não se restringem apenas a estes modos de atravessamentos. Atentar somente a esse olhar para essas mulheres é perpetuar o olhar de colonizador que não enxerga a potência ali existente (BERNARDO, 2005). Por isso, neste tópico, elucidaremos modos de respostas e construções subjetivas na perspectiva da resistência, pois, na tentativa de não definir as mulheres negras por estas mazelas, iremos refletir sobre modos de produção e construção da subjetividade de resistência.

Um conceito importante que nos auxilia na compreensão é o de subjetividade nômade proposto por Braidotti (2002). Segundo a autora, a subjetividade nômade "tem a ver com a simultaneidade das identidades complexas e multidimensionadas" (BRAIDOTTI, 2002, p. 10). Neste modo de configuração subjetiva, o sujeito nômade é aquele que se posiciona através da renúncia, desconstrução das identidades estagnadas e fixas. Braidotti (2002, p.10) traz o conceito de contramemória de Foucault para exemplificar a subjetividade nômade, sendo ela "uma forma de resistir à assimilação ou homologação dentro de formas dominantes de representar a si próprio". E quando pensamos na história das mulheres negras, identificamos uma história de muita luta e resistência desde os primórdios da chegada ao Brasil no período diaspórico.

Podemos compreender que, da mesma forma que o sofrimento pode paralisar, ele também pode ser um impulso a impelir para a luta, a resistência e a ressignificação da dor (SOUZA, 1983; PRESTES, 2013). O nomadismo nos sujeitos e mulheres negras é a tomada de consciência crítica que, por meios de resistência, opõem-se aos mecanismos de branqueamento e anulação étnica, modos esses de pensamento e comportamento codificados (BRAIDOTTI, 2002).

Ao longo do artigo, a autora diz apoiar as figurações de subjetividade nômade, distinguindo tal processo "para agir como uma desconstrução permanente do falologocentrismo eurocêntrico" (BRAIDOTTI, 2002, p.12). E, segue afirmando que o nomadismo no feminismo apoia a multiplicidade, complexidade, anti-essencialismo e antirracismo, ou seja, as feministas nômades são aquelas que desfazem "as estruturas de poder, que sustentam as oposições dialéticas dos sexos, enquanto respeitam a diversidade das mulheres e a multiplicidade dentro de cada mulher" (BRAIDOTTI, 2002, p. 15).

Tal ação nômade de rompimento é evidente ao olharmos para a cosmovisão do Candomblé - uma das religiões africanas disseminadas no Brasil na época diaspórica. 
Quando as mulheres negras, pelo processo diaspórico, chegam ao Brasil, são elas que detêm o poder religioso no Candomblé, dotadas do axé e referenciadas na matrilinearidade. Elas detêm também o sustento das famílias, mantendo e auxiliando no cuidado com as famílias das outras mulheres negras, sendo referência da matrifocalidade (BERNARDO, 2005). Em ambos os exemplos, as mulheres negras rompem com o padrão da subjetividade sedentária e produzem alternativas de resistência ao patriarcado na religiosidade e na família. Rompem também com os padrões e delineiam a subjetividade nômade quando assumem a afro-brasileiridade, o cabelo black, a sua negritude, criando seus modos de ir e vir e ser, tanto individual quanto coletivamente, nos movimentos feministas negros, Slams, redes de amor e afeto, entre outros moveres das mulheres negras contemporâneas.

Além das compreensões de Braidotti (2002), há relevantes considerações do CFPs (2017) sobre as táticas de enfrentamento da população negra. Quando o indivíduo negro tem a consciência de que há uma violência racial real - que o impede e o determina na realidade social -, além de que no âmbito familiar é ensinado o pertencimento à cultura afro-brasileira, o negro e a negra, como resposta à violência que é sentida através do racismo, podem responder em forma de luta. Esta atitude de militância não se torna obrigatória, mas pode ser entendida, em consonância com o CFP (2017), como uma ação possível de ser emitida pela população negra. E esta luta, como resposta, consiste em refletir e questionar as práticas opressoras instituídas. Luta que a impele a identificar e criminalizar tais atitudes racistas, que a faz resistir e conscientizar mais pessoas da existência até hoje de tais atos atrozes e prejudiciais. Para lutar contra o racismo é necessário refletir e construir a consciência de que a violência racial é real. Portanto, consideremos que o conhecimento sobre a existência do racismo e o pertencimento à cultura afro-brasileira pode levar tal população a táticas de enfrentamento.

Outro ponto importante, que nos explica ainda o CFP (2017) sobre a resposta do povo negro ao sofrimento, é o pertencimento ao seu grupo racial. Este fazer parte do grupo negro gera um aumento na autoconfiança e na propensão da formação de uma subjetividade que se identifica com suas características grupais, fenotípicas e ancestrais (ANSARA, 2008). O que também explica a resposta emitida ao sofrimento em forma de resistência. Se há a consciência de onde se vem e de onde se pertence é formada uma 
identidade própria e, quando tal construção subjetiva é agregada à consciência de que existe uma violência racial, o indivíduo consegue se posicionar contra e resistir.

Quando há então uma produção social e cultural em função de lutar e desvelar o racismo, isso pode afetar o negro e a negra positivamente, o que possibilita o fortalecimento psíquico e político, além de oferecer ao indivíduo branco a consciência do lugar beneficiário que ele ocupa na sociedade e como esses privilégios perpetuam o lugar dos negros na linha de frente das desigualdades e violências (CFP, 2017).

Frente ao sofrimento dessas mulheres, além de existir o processo de enfrentamento - que pode surgir a partir do pertencimento ao grupo ou da consciência da presença da violência racial e da subjetividade nômade - há uma outra estratégia utilizada por elas. Essa outra estratégia de enfrentamento encontra-se presente no processo de resiliência, a qual é observada na forma como as mulheres negras têm enfrentado a violência racial e de gênero.

Prestes (2013) denomina o processo da resiliência como o enfretamento às consequências do racismo, um processo potencializador que lida com a consequência da exposição ao sofrimento impelido a essa mulher negra. Na expectativa de não se paralisar, mas de prosseguir, o processo de resiliência acontece. É encontrada nos grupos e individualmente, tornando-se um processo de superação e fortalecimento psíquico frente a eventos traumáticos (ANGST, 2009).

Ressaltamos que não se resume a resiliência a um tipo de habilidade individual da pessoa ou do grupo, e também não há o impedimento do prejuízo. Entretanto, podemos entender que a resiliência vinculada à população negra e, em especial, às mulheres negras, trata-se do processo "da superação de grandes adversidades e vulnerabilidades saindo a pessoa mais fortalecida e encontrando um sentido na experiência" (PRESTES, 2013, p. 58). Considera-se que a resiliência não é uma supressão dos afetos e sintomas psíquicos prejudiciais, "mas um efeito menos devastador das fontes de stress intenso, podendo chegar à exaustão, mas não sucumbindo" (PRESTES, 2013, p. 58). Sendo assim, a resiliência nessas mulheres refere-se ao acesso em seus recursos pessoais e coletivos, que vai desde a autoconfiança e otimismo, até a autonomia e sentido de vida, elencando, então, este fenômeno da resiliência como um processo de ressignificação, reorganização e superação que, através da transcendência no seu existir, ultrapassa a experiência do contexto desintegrador e aversivo. 
As contações de histórias, assim como o fortalecimento da cultura e ancestralidade presentes na família dessas mulheres, são exemplos de processos que ressignificam o sentindo de ser negra, fugindo do afastamento que o racismo propõe e potencializando o processo de resiliência (PRESTES, 2013). Assim, como os suicídios e rebeliões, as comunidades quilombolas, na época da escravidão, eram estratégias e processos potencializadores de resiliência. Hoje nos movimentos políticos sociais, podemos também identificar esta característica de empoderamento e resistência.

As mulheres negras, por nascerem, crescerem e viverem expostas a vulnerabilidades, tornam-se guerreiras e, quando dizemos guerreiras, trazemos o fato de suportarem e vivenciarem situações que as afetam negativamente ao longo da vida, sendo presente o movimento de passarem por estes eventos traumáticos com o menor efeito negativo possível. Desde Tereza de Benguela no Quilombo do Quariterê, são sujeitadas às lutas e guerras diárias, não lhes restando tempo, espaço e permissão para o amor e oportunidades no trabalho em grandes funções de destaque ou de estudos. $\mathrm{O}$ amor e as oportunidades ficam para os brancos, que não necessitam guerrear como as mulheres negras. A sua caracterização de luta não é instinto ou nasce com a sua vida, mas é treino durante as experiências cotidianas, ao longo das gerações, desde antes de Dandara até atualmente (PRESTES, 2013). Frente a todo desamparo que o racismo institucional, intersubjetivo e internalizado as submete, armam-se como negras guerreiras, "para suportarem a sucessão de violências" (PRESTES, 2013, p. 152).

Nesta guerra que segue o feminismo, principalmente o negro, lutando pela saúde das mulheres negras, seus objetivos ainda não foram alcançados. Apesar da necessidade da luta contínua, a união do grupo das mulheres negras e a compatibilidade dos acontecimentos, ou seja, das vivências semelhantes de violência racial, de gênero e de classes, geram fraternidade e luta, a partir dos seus inúmeros fenômenos e processos individuais e grupais, possibilitam a continuidade da resistência e na não paralização no sofrimento. Embora lutando, guerreando e utilizando dos processos de resiliência, os danos psíquicos continuam presente (PRESTES, 2013).

Porém, mesmo mediante aos danos psíquicos ainda presentes, podemos considerar essas mulheres como guerreiras. Segundo Prestes (2013), são guerreiras no aspecto subjetivo quando encaram bravamente a junção de estereótipos atrelados à objetificação de seus corpos, que são associados aos atributos sexuais e satisfações destes desejos. 
Também são guerreiras no lar, pois o abandono paternal que as assolam obriga-as a buscar sustento para suprir as demandas de estudo, afeto e do lar. Tornam-se guerreiras diante do padrão estético estabelecido socialmente e a partir da conscientização política, resgatam sua estética diante da violência do branqueamento que as angustia, pois não são o padrão da beleza hegemônico, estão, muitas vezes, nas situações e relacionamentos preteridos. Por fim, são guerreiras no amor, pois se defendem para evitar ataques às feridas ainda abertas, ou seja, até para amar são guerreiras, expostas a violências simbólicas. Em outras palavras, aqueles que se dispõem a estabelecer uma relação estável com elas precisam refletir seus privilégios e dissolvê-los. Dessa forma, essas mulheres são guerreiras, uma vez que, nos muitos processos de resiliência, encontram formas de ressignificar-se e dar um sentido para a experiência, fazendo com que o impacto seja menos negativo possível.

As famílias negras podem carregar esta característica do processo de resiliência, ou seja, uma capacidade de ressignificação. Através da solidariedade, elas se sustentam, não necessariamente por laços sanguíneos, mas por aquele (a) que tiver afetividade para exercer a organização desta família. Encontramos nessas famílias uma maneira de organizar outra tática de enfretamento dessas mulheres. Nascimento (2008) as denomina como as "mulheres-faróis", responsáveis por tornar suportável quando não se pode mais ser confortável o ambiente deste lar, papel de mãe que é praticado por aquelas que se colocam dispostas para oferecer os braços fortes para amparar. A família é um lugar considerável e significativo de enfrentamento delas na sociedade, lugar onde buscam respaldo e fortalecimento para seguir e lutar diariamente (TOKITA, 2013).

Em outra posição de luta, encontramos a participação nos movimentos sociais. A participação das mulheres negras nos movimentos sociais feministas auxilia na construção da identidade negra positivamente, o que propõe a reivindicação de direitos e melhoria na condição de vida destas, ou seja, enfrentamento. Nestes movimentos sociais, encontram muitas vezes a oportunidade de ocupação e manifestação.

Tokita (2013) afirma que tais movimentos são espaços de cura para as mulheres negras, locais de fortalecimento subjetivo que oferecem a oportunidade de surgimento de novas histórias para as mesmas e para as que virão. Também afirma que os movimentos das mulheres têm ganhado força e diversas nuances na luta social igualitária. 
Nessa militância política, além de feridas curadas, direitos foram conquistados. Como ilustra o CFP (2017), consideramos tais conquistas: debater o assunto e trazer a consciência da existência do racismo; implementação de leis que definem o racismo como crime; inclusão da história africana no Ensino Público; criação de movimentos sociais; criação de políticas de ações afirmativas em universidades e serviços públicos. Muitas conquistas foram alcançadas, o que não limita a existência da necessidade de buscar outras mais.

Além destas estratégias existentes e utilizadas na e pela população negra, no âmbito de políticas conquistadas por tal população, identificamos no ano de 2012 a produção do guia de enfrentamento ao racismo institucional formulado pelo Geledés (Instituto da Mulher Negra), no qual é apresentado este compromisso assumido no papel pelo Estado Brasileiro na época. Este projeto é integrado no objetivo do programa 2034: “Enfrentamento ao racismo e promoção da Igualdade Racial". Neste compromisso, que o Estado assumiu, era previsto lutar contra a violência racial e sua prevenção nas instituições privadas e públicas, promovendo a igualdade e pluralidade étnico-racial. $\mathrm{O}$ Guia expõe que a meta de tal projeto é ampliar o número de organizações que aderem às prevenções e ao enfrentamento ao racismo institucional. Apesar de esta política estar presente no plano brasileiro, o Guia deixa claro que ainda faltam meios e caminhos para efetivar o planejamento (GELEDÉS, 2012).

A existência de tal ação significa que a luta dos movimentos negros tem chegado também no âmbito político institucional, conquistando direitos e ações de combate ao racismo, ressaltando que a política estabelecida na época oportunizava e apoiava as lutas dos movimentos sociais. Nesta perspectiva, houve a criação das políticas de ações afirmativas através de cotas nos concursos públicos e universidades, na qual cerca de $20 \%$ é reservada à população negra. Sabemos que estas políticas conquistadas, como também a lei $N^{o} 7.716$ de 5 de janeiro de 1989, que classifica discriminação e/ou preconceito de cor, etnia, religião como crime, e a lei $\mathrm{N}^{\mathrm{o}} 10.639 / 03$ que antes tornava obrigatório - hoje com a modificação foi retirada a obrigatoriedade - o ensino da história e cultura afrobrasileira e africana nas escolas, ainda não extinguem todas as consequências de desigualdade social que os negros e negras brasileiras enfrentam em decorrência do racismo. Ainda, é necessário conquistar mais políticas públicas voltadas a tal população 
e produzir conscientização da existência e necessidade destas políticas como reparação do impacto diaspórico.

Neste sentido, o atual momento político que se instaura no país, caracterizado como um governo de extrema direita representado pelo Presidente Jair Messias Bolsonaro, ascende o autoritarismo e o neoliberalismo. Tais fatos atingem diretamente a população negra, pois houve, por exemplo, a derrubada de ministérios e secretarias importantes para a população em questão.

Pensar a situação política vigente está de acordo com o que o código de ética de Psicologia aborda como uns dos princípios fundamentais da profissão: "O psicólogo atuará com responsabilidade social, analisando crítica e historicamente a realidade política econômica, social e cultural" (CFP, 2017, p. 10). Abordando também neste mesmo princípio a responsabilidade com o rompimento de situações e contextos que perpetuam violências, desigualdades, humilhações e desqualificações. Isto vem ao encontro com a proposta de discutir neste tópico e durante o artigo tais questões através da Psicologia.

\section{CONSIDERAÇÕES FINAIS}

Marcadas pela dor, a partir das táticas de enfrentamento de si e do grupo, estas mulheres reescrevem suas histórias. Apesar do contexto político difícil, com esperança, ressurgem, fazendo o futuro das que virão na certeza de que, com luta e resistência, irão construir uma nova história da mulher negra e do povo negro brasileiro. Na busca de um país antirracista, antissexista, e de um lugar que as reconheça e que seja delas, renascem, ressurgem e erguem-se entre feridas, cambaleando, mas sem sucumbir, pois, são mulheres negras guerreiras.

Permeadas pelos desdobramentos de resistir, ressignificar-se na família, nos movimentos sociais, na cultura e onde estiverem, a partir do processo de resiliência, de consciência do racismo, da fraternidade, solidariedade, união e da subjetividade nômade, as mulheres negras brasileiras vivem, existem, transcendem e fazem história.

Porém, como visto, há fatores sociais determinantes de padrões que anulam étnica e historicamente as subjetividades negras. A existência de uma estrutura racista e sexista pode colocá-las em papéis e lugares sociais de caráter humilhante, desigual e 
desqualificador. Práticas institucionais, internalizadas e intersubjetivas da violência racial impelem sofrimento psíquico considerável, levando-as a um esgotamento psíquico, baixa autoestima e até mesmo ao suicídio. Tais práticas, quando entrecruzadas ao gênero e à classe social, determinam negativamente a subjetividade dessas mulheres. Além disso, o lócus social ocupado por tal população elicia um sofrimento ético-político, pois é uma população exposta à pobreza, desemprego, vítimas de homicídios, abusos e não oportunidades.

Discutir a temática faz-se importante para a Psicologia, sociedade e o momento político vigente. Como afirma o CFP (2017), o fomento de discussões sobre a temática étnico-racial pode contribuir positivamente para os indivíduos e população negra, além de romper com as estruturas coloniais existentes.

Assumindo nosso compromisso com a Psicologia, sociedade e sujeito, este artigo se construiu como a possibilidade de aproximação das subjetividades de mulheres negras, com o objetivo de nos atermos ao sofrimento desta população e o quanto a classe profissional precisa comprometer-se com práticas descolonizadoras, além de conhecer os processos de enfrentamento e utilizá-los como fomento e oportunidade de táticas para o menor prejuízo frente às violências que essas mulheres experienciam.

\section{REFERÊNCIAS BIBLIOGRÁFICAS}

ANGST. Rosana. Psicologia e Resiliência: Uma revisão de literatura. Psico Orgum, v. 27, n. 58, 2009, p. 253-260.

ANSARA. Soraia. Memória Política, Ditadura Militar e Repressão no Brasil. Curitiba: Juruá, 2008.

BERNARDO, Terezinha. O candomblé e o poder feminino. Revista de Estudos da Religião, v. 1, n. 2, 2005 p. 1-21. Disponível em 〈https://www.pucsp.br/rever/rv2_2005/p_bernardo.pdf> 23/05/2020.

BRAIDOTTI, Rosi. Diferença, diversidade e subjetividade nômade. Revista Estudos feministas, v. 1, n. 2, 2002, p. 1-16.

CARNEIRO, Sueli. Enegrecer o feminismo: a situação da mulher negra na América Latina a partir de uma perspectiva de gênero. In: TAKANO, Empreendedores Sociais. Racismos contemporâneos. Rio de Janeiro: TAKANO, 2003.

CFP. Relações raciais: referências técnicas para atuação de psicólogas/os. Brasília: CFP, 2017. 
COSTA, Thainá da Silva; CANTELLE, Lilian. Mulheres negras: Entre o sofrer e o resistir. Revista Interciência, v. 1, n. 1, 2018, p. 48-54.

CREENSHAW, Kimberle. A interseccionalidade na discriminação de raça e gênero. In: UNIFEM, Cruzamento. Raça e gênero. Brasília: UNIFEM, 2004.

FANON, Frantz. Pele negra, máscaras brancas. Salvador: EDUFUBA, 2008.

GELEDÉS, Instituto Da Mulher Negra. Guia de enfrentamento do racismo institucional. Br: Trama Design, 2012.

GONÇALVES, Renata. O feminismo marxista de Heleieth Saffioti. São Paulo. Revista Lutas Sociais, n. 27, 2011, p. 119-131.

GONZALEZ, Lélia. Por um feminismo afro-latino-americano. In: CÍRCULO PALMARINO, Caderno de formação política do círculo palmarino n.1 batalha de ideias. São Paulo: CírCulo Palmarino, 2011.

GUIMARÃES, Antonio Sergio Alfredo. Como trabalhar com raça em Sociologia. Revista Educação e Pesquisa, v. 29, n. 1, 2003, p. 93-107.

IPEA. Instituto de Pesquisa Econômica Aplicada. Retratos das desigualdades de gênero e raça. Brasília: IPEA, 2015.

LEÃO, Ryane. Tudo nela brilha e queima: poemas de luta e amor. São Paulo: Planeta Brasil, 2017.

LIMA, Ana Nery Correia. Mulheres militantes negras: a interseccionalidade de gênero e raça na produção das identidades contemporâneas. In: ANINTER-SH, Resumo do II Congresso Internacional Interdisciplinar em Sociais e Humanidades. Belo horizonte: ANINTER-SH, 2013.

LIMA JUNIOR, Antônio Teireixa; CHERFEM, Carolina Orquiza. Igualdade Racial. In: IPEA, Boletim políticas sociais acompanhamento e análise n. 24. Brasília: IPEA 2016.

NASCIMENTO, Beatriz. A mulher negra no mercado de trabalho. In: RATTS, Alex, Eu sou Atlântica: sobre a trajetória de vida de Beatriz Nascimento. São Paulo: Instituto Kuanza, 2007.

PRESTES, Clélia Rosana dos Santos. Feridas até o coração, erguem-se negras guerreiras. Resiliência em mulheres negras: Transmissão psíquica e pertencimentos. Dissertação (Mestrado em Psicologia Social), Universidade de São Paulo. São Paulo: USP, 2013.

RIBEIRO, Djamila. O que é: Lugar de fala? Belo Horizonte: Letramento, 2017.

ROLNIK, Sueli. Uma insólita viagem à subjetividade: fronteiras com aética e a cultura. 1997.

SAFFIOTI, Heleith. Diferença ou indiferença: gênero, raça/etnia, classe social. In: COORDENADORIA ESPECIAL DA MULHER, Políticas públicas e igualdade de gênero. São Paulo: Coordenadoria Especial da Mulher, 2004. 
SAFFIOTI, Heleith. Mulher na sociedade de classes: mito e realidade. Petrópolis: Editora Vozes, 1976.

SANTOS, Juciara Alves dos. Sofrimento psíquico gerado pelas atrocidades do racismo. Revista da $A B P N$, v. 10 , n. 24, 2017, p. 148-165.

SAWAIA, Bader Burihan. O sofrimento ético-político como categoria de análise da dialética exclusão/inclusão. In: SAWAIA, Bader Burihan, et al. As artimanhas da exclusão: uma análise ético-psicossocial da desigualdade. Petrópolis: VOZES, 1999.

SCHUCMAN, Lia Vainer. Sim, nós somos racistas: Estudo psicossocial da branquitude paulistana. Revistas Psicologia \& Sociedade, v. 26, n. 1, 2014, p. 83-94.

SOUZA, Neusa Santos. Tornar-se negro. Rio de Janeiro: Edições Graal, 1983.

THEODORO, Helena. Mulher negra, cultura e identididade afro-brasileira. In: NASCIMENTO, Elisa Larkin, Guerreira de natureza: mulher negra, religiosidade e ambiente. São Paulo: Sankofa, 2008.

TOKITA, Márcia Figueiredo. Mulheres negras. In: Anais do V Simpósio Internacional Lutas Sociais na América Latina, Feminismos, sexualidade e marxismos na América Latina. Londrina: GRUPO DE ESTUDOS DA POLÍTICA DA AMÉRICA LATINA, 2013.

VEIGA, Lucas. As diásporas da bixa preta: sobre ser negro e gay no Brasil. Revista Tabuleiro de Letra, v. 12, n. 1, 2018, p. 78-88.

WEDDERBURN, Carlos Moore. O racismo através da história: da antiguidade à modernidade. Belo Horizonte: Editora Mazza, 2007.

ZAMORA, Maria Helena Rodrigues Navas. Desigualdade racial, racismo e seus efeitos. Revista de Psicologia Fractal, v. 24, n. 3, 2012, p. 563-578.

Recebido em: 02/12/2020

Aprovado em: 30/09/2021 